\title{
ISU-ISU KONTEMPORER PENDIDIKAN ISLAM ANAK USIA DINI
}

\author{
Fatkhul Mubin \\ fatkhulmubin90@gmail.com
}

\section{A. PENDAHULUAN}

Pendidikan adalah proses yang tanpa akhir (Education is the process without end), dan pendidikan merupakan proses pembentukan kemampuan dasar yang fundamental, baik menyangkut daya pikir (daya intelektual) maupun daya emosional (perasaan) yang diarahkan kepada tabi'at manusia dan kepada sesamanya. ${ }^{1}$

Pendidikan anak usia dini (PAUD) merupakan fondasi bagi perkembangan kualitas sumber daya manusia selanjutnya. Karena itu peningkatan penyelenggaraan PAUD sangat memegang peranan yang penting untuk kemajuan pendidikan di masa mendatang. Arti penting mendidik anak sejak usia dini dilandasai dengan kesadaran bahwa masa kanak-kanak adalah masa keemasan (the Golden Age), karena dalam rentang usia dari 0 sampai 5 tahun, perkembangan fisik, motorik dan berbahasa atau linguistik seorang anak akan tumbuh dengan pesat. Selain itu anak pada usia 2 sampai 6 tahun dipenuhi dengan senang bermain.

\section{Rumusan Masalah}

1. Apa Hakikat Pendidikan Anak Usia Dini?

2. Apa Pentingnya Pendidikan Usia Dini Untuk Perkembangan Pola Pikir Anak?

3. Bagaimana Prinsip Pendidikan Anak Usia Dini?

4. Apa Fungsi dan Tujuan di adakannya Pendidikan Anak Usia Dini?

Tujuan Pembahasan

1. Untuk mengetahui hakikat Pendidikan Anak Usia Dini

2. Untuk mengetahui pentingnya Pendidikan Usia Dini untuk perkembangan pola pikir anak

3. Untuk mengetahui Prinsip Pendidikan Anak Usia Dini

4. Untuk mengetahui fungsi dan tujuan di adakannya Pendidikan Anak Usia Dini

${ }^{1}$ Syaiful Sagala, Etika dan Moralitas Pendidikan (Peluang dan Tantangan), (Jakarta: KENCANA, 2013), 38. 


\section{A. PEMBAHASAN}

\section{Hakikat Pendidikan Anak Usia Dini}

Konsep bermain sambil belajar serta belajar sambil bermain pada PAUD merupakan pondasi yang mengarahkan anak pada pengembangan kemampuan yang lebih beragam, sehingga di kemudian hari anak bisa berdiri kokoh dan menjadi sosok manusia yang berkualitas.

Pendidikan anak usia dini (PAUD) merupakan jenjang pendidikan sebelum jenjang pendidikan dasar yang merupakan suatu pembinaan yang ditujukan bagi anak sejak lahir sampai dengan usia enam tahun yang dilakukan melalui pemberian rangsangan pendidikan untuk membantu pertumbuhan dan perkembangan jasmani dan rohani agar anak memliki kesiapan dalam memasuki pendidikan lebih lanjut, yang diselenggarakan pada jalur formal, nonformal dan informal. ${ }^{2}$

Dalam hal ini M. Hariwijaya (2007:14), mengemukakan bahwa PAUD dapat diartikan sebagai salah satu bentuk jalur pendidikan dari usia 0-6 tahun, yang diselenggarakan secara terpadu dalam satu program pembelajaran agar anak dapat mengembangkan segala guna dan kreativitasnya sesuai dengan karakteristik perkembangannya.

Pendidikan anak usia dini merupakan salah satu bentuk penyelenggaraan pendidikan yang menitikberatkan pada peletakan dasar ke arah pertumbuhan dan perkembangan fisik (koordinasi motorik halus dan kasar), kecerdasan (daya pikir, daya cipta, kecerdasan emosi, kecerdasan spiritual), sosio emosional (sikap dan perilaku serta agama) bahasa dan komunikasi, sesuai dengan keunikan dan tahap-tahap perkembangan yang dilalui oleh anak usia dini.

Catron dan allen (1999:23-26) menyebutkan bahwa terdapat 6 aspek perkembangan anak usia dini, yaitu kesadaran personal, kesehatan emosional, sosialisasi, komunikasi, kognisi dan ketrampilan motorik sangat penting dan harus dipertimbangkan sebagai fungsi interaksi.

2 Saihu, S. (2019). RINTISAN PERADABAN PROFETIK UMAT MANUSIA MELALUI PERISTIWA TURUNNYA ADAM AS KE-DUNIA. Mumtaz: Jurnal Studi Al-Quran dan Keislaman, 3(2), 268-279,

Saihu, S. (2019). Pendidikan Pluralisme Agama: Kajian tentang Integrasi Budaya dan Agama dalam Menyelesaikan Konflik Sosial Kontemporer. Jurnal Indo-Islamika, 9(1), 67-90,

Saihu, S. (2019). IMPLEMENTASI MANAJEMEN BALANCED SCORECARD DI PONDOK PESANTREN JAM'IYYAH ISLAMIYYAH TANGERANG SELATAN. Mumtaz: Jurnal Studi Al-Quran dan Keislaman, 3(1), 1-22.

Saihu, S. (2019). KOMUNIKASI PENDIDIK TERHADAP ANAK BERKEBUTUHAN KHUSUS DI SEKOLAH KHUSUS ASY-SYIFA LARANGAN. Andragogi: Jurnal Pendidikan Islam dan Manajemen Pendidikan Islam, 1(3), 418-440.

Saihu, S., \& Marsiti, M. (2019). PENDIDIKAN KARAKTER DALAM UPAYA MENANGKAL RADIKALISME DI SMA NEGERI 3 KOTA DEPOK, JAWA BARAT. Andragogi: Jurnal Pendidikan Islam dan Manajemen Pendidikan Islam, 1(1), 23-54.

Saihu, S. (2019). KONSEP MANUSIA DAN IMPLEMENTASINYA DALAM PERUMUSAN TUJUAN PENDIDIKAN ISLAM MENURUT MURTADHA MUTHAHHARI. Andragogi: Jurnal Pendidikan Islam dan Manajemen Pendidikan Islam, 1(2), 197-217.

Saihu, S., \& Rohman, B. (2019). PEMBENTUKAN KARAKTER MELALUI MODEL PENDIDIKAN TRANSFROMATIFE LEARNING PADA SANTRI DI PONDOK PESANTREN NURUL IKHLAS BALI. Edukasi Islami: Jurnal Pendidikan Islam, 8(02), 435-452. 
Anak usia dini adalah kelompok anak yang berada dalam proses pertumbuhan dan perkembangan yang bersifat unik, dalam arti memiliki pola pertumbuhan dan perkembangan (koordinasi motorik halus dan kasar), intelegensi (daya pikir, daya cipta, kecerdasan emosi, dan kecerdasan spiritual), sosial emosional (sikap dan perilaku serta agama), bahasa dan komunikasi yang khusus sesuai dengan tingkat pertumbuhan dan perkembangan anak. Berdasarkan keunikan dalam pertumbuhan dan perkembangannya, anak usia dini terbagi dalam empat tahapan, yaitu (a) masa bayi lahir sampai 12 bulan, (b) masa toddler (batita) usia 1-3 tahun, (c) masa prasekolah usia 3-6 tahun, (d) masa kelas awal SD 6-8 tahun. ${ }^{3}$

Pertumbuhan dan perkembangan anak usia dini perlu diarahkan pada peletakan dasar-dasar yang tepat bagi pertumbuhan dan perkembangan manusia seutuhnya, yaitu pertumbuhan dan perkembangan fisik, daya pikir, daya cipta, sosial emosional, bahasa dan komunikasi yang seimbang sebagai dasar pembentukan pribadi yang utuh. ${ }^{4}$

Kreativitas tidak dipandang sebagai perkembangan tambahan, melainkan sebagai komponen yang integral dari lingkungan bermain yang kreatif. Pertumbuhan anak ada 6 aspek perkembangan di bawah ini membentuk fokus sentral dan pengembangan kurikulum bermain pada anak usia dini.

1. Kesadaran Personal

Permainan yang kreatif memungkinkan perkembangan kesadaran personal. Bermain mendukung anak untuk tumbuh secara mandiri dan memiliki kontrol atas lingkungannya. Melalui bermain anak dapat menemukan hal yang baru, berekslorasi, meniru dan mempraktikan kehidupan sehari-hari sebagai sebuah langkah dalam membangun ketrampilan menolong dirinya sendiri, ketrampilan ini membuat anak kompeten. ${ }^{5}$

${ }^{3}$ Dadan Suryana, Stimulasi \& Aspek Perkembangan Anak, (Jakarta: Kencana, 2016), 26.

${ }^{4}$ Bambang Hartoyo, Konsep Dasar Pendidikan Anak Usia Dini, (Materi Tutor dan Pengelola Pendidikan Anak Usia Dini, di BPPLSP Regional III Jawa Tengah, 2004), 3.

${ }^{5}$ Saihu, S., \& Taufik, T. (2019). PERLINDUNGAN HUKUM BAGI GURU. Al Amin: Jurnal Kajian Ilmu dan Budaya Islam, 2(2), 105-116.

Saihu, S. (2020). KONSEP PEMBAHARUAN PENDIDIKAN ISLAM MENURUT FAZLURRAHMAN. Andragogi: Jurnal Pendidikan Islam dan Manajemen Pendidikan Islam, 2(1), 82-95.

Saihu, S. (2020). ETIKA MENUNTUT ILMU MENURUT KITAB TA'LIM MUTA'ALIM. $A l$ Amin: Jurnal Kajian Ilmu dan Budaya Islam, 3(1), 99-112.

Saihu, Aziz, A., Mubin, F., \& Sarnoto, A. Z. (2020). Design of islamic education based on local wisdom (An analysis of social learning theories in forming character through ngejot tradition in bali). International Journal of Advanced Science and Technology, 29(6), 1278-1293.

Ronaldo, R., Zulfikar, A., Saihu, Ismail, \& Wekke, I. S. (2020). International relations of the asia pacific in the age of trump. Journal of Environmental Treatment Techniques, 8(1), 244-246.

Saihu, M. M., \& Aziz, A. (2020). Implementasi Metode Pendidikan Pluralisme Dalam Mata Pelajaran Pendidikan Agama Islam. Belajea; Jurnal Pendidikan Islam, 5(1), 131-150.

Saihu, M. (2019). Urgensi 'Urf dalam Tradisi Male dan Relevansinya dalam Dakwah Islam di Jembrana-Bali. Jurnal Bimas Islam, 12(1), 173-201. 


\section{Pengembangan Emosi}

Melalui bermain anak dapat belajar menerima, berekspresi dan mengatasi masalah dengan cara yang positif. Bermain juga memberikan kesempatan pada anak untuk mengenal diri mereka sendiri dan untuk mengembangkan pola perilaku yang memuaskan dalam hidup.

3. Membangun Sosialisasi

Bermain memberikan jalan bagi perkembangan sosial anak ketika berbagi dengan anak yang lain. Bermain dapat menumbuhkan dan meningkatkan rasa sosialisasi anak.

4. Pengembangan Komunikasi

Bermain merupakan alat yang paling kuat untuk membelajarkan kemampuan berbahasa anak. Melalui komunikasi inilah anak dapat memperluas kosakata dan mengembangkan daya penerimaan serta pengekspresian kemampuan berbahasa mereka melalui interaksi dengan anak-anak lain dan orang dewasa pada situasi bermain spontan.

5. Pengembangan Kognitif

Bermain dapat memenuhi kebutuhan anak untuk secara aktif terlibat dengan lingkunga, untuk bermain dan bekerja dalam menghasilkan suatu karya, serta untuk memenuhi tugas-tugas perkembangan kognitif lainnya. Selama bermain, anak menerima pengalaman baru, memanipulasi bahan dan alat, berinteraksi dengan orang lain dan mulai merasakan dunia mereka.

6. Pengembangan Kemampuan Motorik

Kesempatan yang luas untuk bergerak, pengalaman belajar untuk menemukan, aktivitas sensori motor yang meliputi penggunaan otot-otot besar dan kecil memungkinkan anak untuk memenuhi perkembangan peseptual motorik.

Saihu, S. (2020). The Effect of Using Talking Stick Learning Model on Student Learning Outcomes in Islamic Primary School of Jamiatul Khair, Ciledug Tangerang. Tarbawi: Jurnal Keilmuan Manajemen Pendidikan, 6(01), 61-68.

Saihu, S. (2020). Pendidikan sosial yang terkandung dalam Surat At-Taubah Ayat 71-72. Edukasi Islami: Jurnal Pendidikan Islam, 9(01), 127-148. 


\section{B. Pentingnya pendidikan usia dini untuk perkembangan pola pikir anak}

Berdasarkan hasil penelitian sekitar 50\% kapabilitaas kecerdasan orang dewasa telah terjadi ketika anak berumur 4 tahun, $80 \%$ telah terjadi perkembangan yang pesat tentang jaringan otak ketika anak berumur 8 tahun dan mencapai puncaknya ketika anak berumur 18 tahun, dan setelah itu walaupun dilakukan perbaikan nutrisi tidak akan berpengaruh terhadap perkembangan kognitif. ${ }^{6}$

Hal ini berarti bahwa perkembangan yang terjadi dalam kurun waktu 4 tahun pertama sama besarnya dengan perkembangan yang terjadi pada kurun waktu 14 tahun berikutnya. Sehingga periode ini merupakan periode kritis bagi anak, dimana perkembangan yang diperoleh pada periode ini sangat berpengaruh terhadap perkembangan periode berikutnya hingga masa dewasa.

Menurut Byrnes, pendidikan anak usia dini akan memberikan persiapan anak menghadapi masa-masa ke depannya, yang paling dekat adalah menghadapi masa sekolah. "Saat ini, beberapa taman kanak-kanak sudah meminta anak murid yang mau mendaftar di sana sudah bisa membaca dan berhitung. Di masa PAUD pun sudah mulai diajarkan kemampuan bersosialisasi dan problem solving. Karena kemampuankemampuan itu sudah bisa dibentuk sejak usia dini," jelas Byrnes.

Selanjutnya menurut Byrnes, bahwa pendidikan anak usia dini itu penting, karena di usia inilah anak membentuk pendidikan yang paling bagus. Di usia inilah anak-anak harus membentuk kesiapan dirinya menghadapi masa sekolah dan masa depan. Investasi terbaik yang bisa Anda berikan untuk anak-anak adalah persiapan pendidikan mereka di usia dini.

Menurut Erik Erikson dalam Malcolm Knowles ada tahapantahapan perkembangan psikososial anak yaitu sebagai berikut:

1. Tahap kepercayaan dan ketidak percayaan (trust versus misstrust), yaitu tahap psikososial yang terjadi selama tahun pertama kehidupan. Pada tahap ini,bayi mengalami konflik anatara percaya dan tidak percaya. Rasa

6 Aziz, A., \& Saihu, S. (2019). Interpretasi Humanistik Kebahasaan: Upaya Kontekstualisasi Kaidah Bahasa Arab. Arabiyatuna: Jurnal Bahasa Arab, 3(2), 299-214

Saihu, S. (2019). PENDIDIKAN KARAKTER BERBASIS KEARIFAN LOKAL (STUDI DI JEMBRANA BALI). Edukasi Islami: Jurnal Pendidikan Islam, 8(01), 69-90.

Şahin, C. RELIGIA.

Saihu, S., \& Mailana, A. (2019). Teori pendidikan behavioristik pembentukan karakter masyarakat muslim dalam tradisi Ngejot di Bali. Ta'dibuna: Jurnal Pendidikan Islam, 8(2), 163176.

Mubin, F. KEADILAN DALAM GENDER: KAJIAN KEPEMIMPINAN WANITA DALAM ISLAM1,

Saihu, M. (2019). Merawat Pluralisme Merawat Indonesia (Potret Pendidikan Pluralisme Agama Di Jembrana-Bali). Deepublish.

Mubin, F. (2019). TAFSIR EMANSIPATORIS: PEMBUMIAN METODOLOGI TAFSIR PEMBEBASAN. Mumtaz: Jurnal Studi Al-Quran dan Keislaman, 3(1), 131-151.

Mubin, F. MODEL-MODEL PEMBELAJARAN BERBASIS MADRASAH DAN KEGIATAN LAIN YANG DIPERLUKAN DI DALAMNYA (FAKTOR PENDUKUNGNYA). 
percaya menuntut perasaan nyaman secara fisik dan sejumlah kecil ketakutan serta kekhawatiran akan masa depan.

2. Tahap otonomi dengan rasa malu dan ragu (autonomi versus shame and doubt), yaitu tahap kedua perkembangan psikososial yang berlangsung pada akhir masa bayi dan masa baru pandai berjalan. Setelah memperoleh kepercayaan dari pengasuh mereka, bayi mulai menemukan bahwa perilaku mereka adalah milik mereka sendiri. Mereka mulai menyatakan rasa mandiri atau atonomi mereka dan menyadari kemauan mereka. Jika orangtua cenderung menuntut terlalu banyak atau terlalu membatasi anak untuk menyelidiki lingkungannya, maka anak akan mengalami rasa malu dan ragu-ragu.

3. Tahap prakarsa dan rasa bersalah (initiatif versus guilt), yaitu tahap perkembangan psikososial ketiga yang berlangsung selama tahun pra sekolah. Pada tahap ini anak terlihat sangat aktif, suka berlari, berkelahi, memanjat-manjat, dan suka menantang lingkungannya. Dengan menggunakan bahasa, fantasi dan permainan khayalan, dia memperoleh perasaan harga diri. Bila orangtua berusaha memahami, menjawab pertanyaan anak, dan menerima keaktifan anak dalam bermain, maka anak akan belajar untuk mendekati apa yang diinginkan, dan perasaan inisiatif semakin kuat. Sebaliknya, bila orangtua kurang memahami, kurang sabar, suka memberi hukuman dan menganggap bahwa pengajuan pertanyaan, bermain dan kegiatan yang dilakukan anak tidak bermanfaat maka anak akan merasa bersalah dan menjadi enggan untuk mengambil inisiatif mendekati apa yang diinginkannya.

4. Tahap kerajinan dan rasa rendah diri (industry versus inferiority),yaitu perkembangan yang berada langsung kira-kira tahun sekolah dasar. Pada tahap ini, anak mulai memasuki dunia yang baru, yaitu sekolah dengan segala aturan dan tujuan. Anak mulai mengarahkan energi mereka menuju penguasaan pengetahuan dan keterampilan intelektual.perasaan anak akan timbul rendah diri apabila tidak bisa menguasai keterampilan yang diberikan disekolah.

5. Tahap identitas dan kekacauan identitas (identity versus identity confusion), yaitu perkembangan yang berlangsung selama tahun-tahun masa remaja. Pada tahap ini, anak dihadapkan pada pencarian jati diri. Ia mulai merasakan suatu perasaan tentang identitasnya sendiri, perasaan bahwa ia adalah individu unik yang siap memasuki suatu peran yang berarti ditengah masyarakat baik peran yang bersifat menyesuaikan diri maupun memperbaharui. Apabila anak mengalami krisis dari masa anak kemasa remaja maka akan menimbulkan kekacauan identitas yang mengakibatkan perasaan anak yang hampa dan bimbang.

6. Tahap keintiman dan isolasi (intimacy versus isolation), yaitu perkembangan yang dialami pada masa dewasa. Pada masa ini adalah membentuk relasi intim dengan oranglain. Menurut erikson, keintiman tersebut biasanya menuntut perkembangan seksual yang mengarah pada hubungan seksual dengan lawan jenis yang dicintai. Bahaya dari tidak tercapainya selama tahap ini adalah isolasi, yakni kecenderungan 
menghindari berhubungan secara intim dengan oranglain kecuali dalam lingkup yang amat terbatas.

7. Tahap generativitas dan stagnasi (generativity versus stagnation), yaitu perkembangan yang dialami selama pertengahan masa dewasa. Ciri utama tahap generativitas adalah perhatian terhadap apa yang dihasilkan (keturunan, produk, ide-ide, dan sebagainya) serta pembentukan dan penetapan garis-garis pedoman untuk generasi mendatang. Apabila generativitas tidak diungkapkan dan lemah maka kepribadian akan mundul mengalami pemiskinan dan stagnasi.

8. Tahap integritas dan keputusasaan (integrity versus despair), yaitu perkembangan selama akhir masa dewasa. Integritas terjadi ketika seorang pada tahun-tahun terakhir kehidupannya menoleh kebelakang dan mengevaluasi apa yang telah dilakukan dalam hidupnya selama ini, menerima dan menyesuaikan diri dengan keberhasilan dan kegagalan yang dialaminya, merasa aman dan tentram, serta menikmati hidup sebagai yang berharga dan layak. Akan tetapi, bagi orangtua yang dihantui perasaan bahwa hidupnya selama ini sama sekali tidak mempunyai makna ataupun memberikan kepuasan pada dirinya maka ia akan merasa putus asa.

\section{Prinsip-prinsip Pendidikan Anak Usia Dini}

Dalam mengembangkan pendidikan anak usia dini terdapat prinsip-prinsip yang harus diperhatikan, antara lain: ${ }^{7}$

1. Berorientasi pada perkembangan Anak

Dalam melakukan kegiatan, pendidik perlu memberikan kegiatan yang sesuai dengan tahapan perkembangan ana. Anak merupakan individu yang unik, maka perlu memerhatikan perbedaan secara individual.

2. Berorientasi pada kebutuhan anak

Kegiatan pembelajaran pada anak harus senantiasa berorientasi pada kebutuhan anak. Anak pada usia dini sedang membutuhkan proses belajar untuk mengoptimakan semua aspek perkembangannya. Dengan demikian, pembelajaran hendaknya dilakukan berdasarkan pada perkembangan dan kebutuhan masing-masing ana.

3. Bermain sambil belajar atau belajar seraya bermain

Kegiatan pembelajaran yang disiapkan oleh pendidik hendaknya dilakukan dalam situasi yang menyenangkan dengan menggunakan strategi, metode, materi/bahan, dan media yang menarik serta mudah diikuti anak.

4. Stimulasi terpadu

Perkembangan anak bersifat sistematis, progresif, dan berkesinambungan. Hal ini berarti kemajuan perkembangan satu aspek akan memengaruhi aspek perkembangan lainnya.

5. Lingkungan kondusif

Lingkungan belajar harus diciptakan sedemikian menarik dan menyenangkan serta demokratis sehingga anak selau betah dalam lingkungan sekolah.

6. Menggunakan pendekatan tematik

7 Trianto Ibnu Badar al-Tabany, Desain Pengembangan Pembelajaran Tematik Bagi Anak Usia Dini TK/RA dan Anak Kelas Awal SD/MI, (Jakarta: Kencana, 2011), 73. 
Tema sebagai wadah mengenalkan berbagai konsep untuk mengenal dirinya dan lingkungan sekitarnya.

7. Aktif, kreatif, inovatif dan menyenangkan

Proses pembelajaran yang aktif, kreatif, inovatif dan menyenangkan dapat dilakukan oleh anak yang disiapkan oleh pendidik melalui kegiatan yang menarik, menyenangkan untuk membangkitkan rasa ingin tahu anak dan memotivasi anak untuk berpikir kritis.

\section{Fungsi Dan Tujuan Pendidikan Anak Usia Dini}

Pendidikan adalah proses interaksi antara pendidik dan anak didik dan atau lingkungan secara sadar, teratur, terencana dan sistematis guna membantu pengembangan potensi anak didik secara maksimal. Pengertian ini dianggap lebih lengkap dan memadai daripada pengertian-pengertian tentang pendidikan yang dikemukakan oleh banyak ahli di bidang pendidikan. $^{8}$

\section{Fungsi PAUD}

Fungsi PAUD yang sebenarnya adalah untuk membantu mengembangkan semua potensi anak (fisik, bahasa, intelektual, emosi, sosial, moral, dan agama) dan meletakkan dasar kearah perkembangan sikap, pengetahuan, keterampilan dan daya cipta untuk menyesuaikan diri dengan lingkungannya dan untuk pertumbuhan dan perkembangan selanjutnya. ${ }^{9}$

Berdasarkan tujuan pendidikan anak usia dini dapat ditelaah beberapa fungsi program stimulasi edukasi, yaitu:

1. Fungsi Adaptasi, berperan dalam membantu anak melakukan penyesuaian diri dengan berbagai kondisi lingkungan serta menyesuaikan diri dengan keadaan dalam dirinya sendiri.

2. Fungsi Sosialisasi, berperan dalam membantu anak agar memiliki keterampilan-keterampilan sosial yang berguna dalam pergaulan dan kehidupan sehari-hari di mana ana berada.

3. Fungsi Pengembangan, berkaitan dengan pengembangan berbagai potensi yang dimiliki anak. Setiap unsur potensi yang dimiliki anak membutuhkan suatu situasi atau lingkungan yang dapat menumbuhkankembangkan potensi tersebut kearah perkembangan yang optimal sehingga menjadi potensi yang bermanfaat bagi anak itu sendiri maupun lingkungannya.

4. Fungsi Bermain, berkaitan dengan pemberian kesempatan pada anak untuk bermain, karena pada hakikat nya bermain itu sendiri merupakan hak anak sepanjang rentang kehidupannya. Melalui kegiatan bermain anak akan mengeksplorasi dunianya serta membangun pengetahuannya sendiri.

5. Fungsi Ekonomik, pendidikan yang terencana pada anak merupakan investasi jangka panjang yang dapat menguntungkan pada setiap rentang perkembangan selanjutnya. Terlebih lagi investasi yang dilakukan berada pada masa keemasan (the golden age) yang akan memberikan keuntungan

${ }^{8}$ Suyadi, Manajemen PAUD, (Yogyakarta: Pustaka Pelajar, 2011), 68.

${ }^{9}$ Mukhtar Latif, Orientasi Pendidikan Anak Usia Dini (Teori dan Aplikasi), (Jakarta: Kencana, 2013), 22. 
berlipat ganda. Pendidikan di Taman Kanak-kanak merupakan salah satu peletak dasar bagi perkembangan selanjutnya.

Fungsi lainnya yang perlu diperhatikan, yakni penyiapan bahan perumusan kebijakan dibidang pendidikan anak usia dini; penyiapan bahan perumusan standar, criteria, pedoman, dan prosedur dibidang pendidikan anak usia dini; pemberian bimbingan teknis dan evaluasi dibidang pendidikan anak usia dini; pelaksanaan pemberdayaan peran serta masyarakat dibidang pendidikan anak usia dini; pelaksanaan urusan ketatausahaan Direktorat (Direktorat PAUD, 2000:6). ${ }^{10}$

Pendidikan nasional berfungsi mengembangkan kemampuan dan membentuk watak serta peradaban bangsa yang bermartabat dalam rangka mencerdaskan kehidupan bangsa, bertujuan untuk berkembangnya potensi peserta didik agar menjadi manusia yang beriman dan bertakwa kepada Tuhan YME, berakhlak mulia, sehat, berilmu, cakap, kreatif, dan menjadi warga negara yang demokratis serta bertanggung jawab (UU RI No. 20/2003 BAB II Pasal 3).

\section{Tujuan PAUD}

Pada umumnya tujuan PAUD adalah mengembangkan berbagai potensi anak sejak usia dini sebagai persiapan untuk hidup dan dapat menyesuaikan diri dengan lingkungannya. Adapun tujuan PAUD adalah: ${ }^{11}$

1. Kesiapan anak memasuki pendidikan lebih lanjut

2. Mengurangi angka mengulang kelas

3. Mengurangi angka putus sekolah

4. Mempercepat pencapaian Wajib Belajar Sembilan Tahun

5. Meningkatkan Mutu Pendidikan

6. Mengurangi angka buta huruf muda

7. Memperbaiki derajat kesehatan dan gizi anak usia dini

8. Meningkatkan Indeks Pembangunan Manusia (IPM).

${ }^{10}$ Yuliani Nurani Sujiono, Konsep Dasar Pendidikan Anak Usia Dini, (Jakarta: PT INDEKS, 2009), 46.

${ }^{11}$ Habibi, Analisis Kebutuhan Anak Usia Dini (Buku Ajar S1 PAUD), (Yogyakarta: Deepublish, 2012), 122. 


\section{A. Kesimpulan}

\section{BAB III \\ PENUTUP}

Pendidikan anak usia dini (PAUD) merupakan jenjang pendidikan sebelum jenjang pendidikan dasar yang merupakan suatu pembinaan yang ditujukan bagi anak sejak lahir sampai dengan usia enam tahun yang dilakukan melalui pemberian rangsangan pendidikan untuk membantu pertumbuhan dan perkembangan jasmani dan rohani agar anak memliki kesiapan dalam memasuki pendidikan lebih lanjut, yang diselenggarakan pada jalur formal, nonformal dan informal.

Adapun PAUD memiliki prinsip, diantaranya: Berorientasi pada perkembangan Anak, Berorientasi pada kebutuhan anak, Bermain sambil belajar atau belajar seraya bermain, Stimulasi terpadu, Lingkungan kondusif, Menggunakan pendekatan tematik, Aktif, kreatif, inovatif dan menyenangkan. Karena PAUD memiliki tujuan khusus mengembangkan berbagai potensi anak sejak usia dini sebagai persiapan untuk hidup dan dapat menyesuaikan diri dengan lingkungannya.

\section{B. Saran}

Pendidikan sangat penting bagi setiap manusia, oleh karenanya pendidikan tidak memandang usia muda atau tua. Begitupun dengan PAUD yang merupakan jenjang bagi anak usia 3-6 tahun, dan diusia ini merupakan masa golden age yang sangat berharga bagi perkembangan anak. Meskipun demikian, anak-anak jangan sampai kehilangan masa kecil mereka yang diisi dengan belajar, akan tetapi mereka harus menikmati masa-masa kanak-kanak mereka dengan bermain sambil belajar. Untuk itu dengan adanya PAUD ini, anak-anak terlatih dengan lingkungan belajar yang sedemikian rupa dan siap untuk menambah ilmu mereka di jenjang Sekolah Dasar/Madrasah Ibtidaiyah.

Selanjutnya, dengan adanya Makalah ini semoga bermanfaat untuk penulis dan siapa pun yang membaca karya ilmiah ini, dan penulis berharap semoga makalah ini sebagai pembelajaran bagi penulis di masa yang akan datang. 


\section{DAFTAR PUSTAKA}

al-Tabany, Trianto Ibnu Badar. 2011. Desain Pengembangan Pembelajaran

Aziz, A., \& Saihu, S. (2019). Interpretasi Humanistik Kebahasaan: Upaya Kontekstualisasi Kaidah Bahasa Arab. Arabiyatuna: Jurnal Bahasa Arab, 3(2), 299-214

Habibi. 2012. Analisis Kebutuhan Anak Usia Dini (Buku Ajar S1 PAUD),

Hartoyo, Bambang. 2004. Konsep Dasar Pendidikan Anak Usia Dini, Materi

Jakarta: KENCANA.

Jakarta: Kencana.

Jakarta: Kencana.

Jakarta: PT INDEKS.

Jakarta: PT INDEKS.

Jawa Tengah.

Kencana.

Latif, Mukhtar. 2013. Orientasi Pendidikan Anak Usia Dini (Teori dan Aplikasi),

Mubin, F. (2019). TAFSIR EMANSIPATORIS: PEMBUMIAN METODOLOGI TAFSIR PEMBEBASAN. Mumtaz: Jurnal Studi Al-Quran dan Keislaman, 3(1), 131-151.

Mubin, F. KEADILAN DALAM GENDER: KAJIAN KEPEMIMPINAN WANITA DALAM ISLAM1,

Mubin, F. MODEL-MODEL PEMBELAJARAN BERBASIS MADRASAH DAN KEGIATAN LAIN YANG DIPERLUKAN DI DALAMNYA (FAKTOR PENDUKUNGNYA).

Ronaldo, R., Zulfikar, A., Saihu, Ismail, \& Wekke, I. S. (2020). International relations of the asia pacific in the age of trump. Journal of Environmental Treatment Techniques, 8(1), 244-246.

Sagala, Syaiful. 2013. Etika dan Moralitas Pendidikan (Peluang dan Tantangan).

Şahin, C. RELIGIA.

Saihu, Aziz, A., Mubin, F., \& Sarnoto, A. Z. (2020). Design of islamic education based on local wisdom (An analysis of social learning theories in forming character through ngejot tradition in bali). International Journal of Advanced Science and Technology, 29(6), 1278-1293.

Saihu, M. (2019). Urgensi 'Urf dalam Tradisi Male dan Relevansinya dalam Dakwah Islam di Jembrana-Bali. Jurnal Bimas Islam, 12(1), 173-201.

Saihu, M. (2019). Merawat Pluralisme Merawat Indonesia (Potret Pendidikan Pluralisme Agama Di Jembrana-Bali). Deepublish.

Saihu, M. M., \& Aziz, A. (2020). Implementasi Metode Pendidikan Pluralisme Dalam Mata Pelajaran Pendidikan Agama Islam. Belajea; Jurnal Pendidikan Islam, 5(1), 131-150.

Saihu, S. (2019). IMPLEMENTASI MANAJEMEN BALANCED SCORECARD DI PONDOK PESANTREN JAM'IYYAH ISLAMIYYAH TANGERANG SELATAN. Mumtaz: Jurnal Studi Al-Quran dan Keislaman, 3(1), 1-22.

Saihu, S. (2019). KOMUNIKASI PENDIDIK TERHADAP ANAK BERKEBUTUHAN KHUSUS DI SEKOLAH KHUSUS ASY-SYIFA LARANGAN. Andragogi: Jurnal Pendidikan Islam dan Manajemen Pendidikan Islam, 1(3), 418-440. 
Saihu, S. (2019). KONSEP MANUSIA DAN IMPLEMENTASINYA DALAM PERUMUSAN TUJUAN PENDIDIKAN ISLAM MENURUT MURTADHA MUTHAHHARI. Andragogi: Jurnal Pendidikan Islam dan Manajemen Pendidikan Islam, 1(2), 197-217.

Saihu, S. (2019). PENDIDIKAN KARAKTER BERBASIS KEARIFAN LOKAL (STUDI DI JEMBRANA BALI). Edukasi Islami: Jurnal Pendidikan Islam, 8(01), 69-90.

Saihu, S. (2019). Pendidikan Pluralisme Agama: Kajian tentang Integrasi Budaya dan Agama dalam Menyelesaikan Konflik Sosial Kontemporer. Jurnal Indo-Islamika, 9(1), 67-90,

Saihu, S. (2019). RINTISAN PERADABAN PROFETIK UMAT MANUSIA MELALUI PERISTIWA TURUNNYA ADAM AS KE-DUNIA. Mumtaz: Jurnal Studi Al-Quran dan Keislaman, 3(2), 268-279,

Saihu, S. (2020). ETIKA MENUNTUT ILMU MENURUT KITAB TA'LIM MUTA'ALIM. Al Amin: Jurnal Kajian Ilmu dan Budaya Islam, 3(1), 99112.

Saihu, S. (2020). KONSEP PEMBAHARUAN PENDIDIKAN ISLAM MENURUT FAZLURRAHMAN. Andragogi: Jurnal Pendidikan Islam dan Manajemen Pendidikan Islam, 2(1), 82-95.

Saihu, S. (2020). Pendidikan sosial yang terkandung dalam Surat At-Taubah Ayat 71-72. Edukasi Islami: Jurnal Pendidikan Islam, 9(01), 127-148.

Saihu, S. (2020). The Effect of Using Talking Stick Learning Model on Student Learning Outcomes in Islamic Primary School of Jamiatul Khair, Ciledug Tangerang. Tarbawi: Jurnal Keilmuan Manajemen Pendidikan, 6(01), 6168.

Saihu, S., \& Mailana, A. (2019). Teori pendidikan behavioristik pembentukan karakter masyarakat muslim dalam tradisi Ngejot di Bali. Ta'dibuna: Jurnal Pendidikan Islam, 8(2), 163-176.

Saihu, S., \& Marsiti, M. (2019). PENDIDIKAN KARAKTER DALAM UPAYA MENANGKAL RADIKALISME DI SMA NEGERI 3 KOTA DEPOK, JAWA BARAT. Andragogi: Jurnal Pendidikan Islam dan Manajemen Pendidikan Islam, 1(1), 23-54.

Saihu, S., \& Rohman, B. (2019). PEMBENTUKAN KARAKTER MELALUI MODEL PENDIDIKAN TRANSFROMATIFE LEARNING PADA SANTRI DI PONDOK PESANTREN NURUL IKHLAS BALI. Edukasi Islami: Jurnal Pendidikan Islam, 8(02), 435-452.

Saihu, S., \& Taufik, T. (2019). PERLINDUNGAN HUKUM BAGI GURU. $A l$ Amin: Jurnal Kajian Ilmu dan Budaya Islam, 2(2), 105-116.

Sujiono, Yuliani Nurani. 2009. Konsep Dasar Pendidikan Anak Usia Dini, Sujiono, Yuliani Nurani. 2009. Konsep Dasar Pendidikan Anak Usia Dini, Suryana, Dadan. 2016. Stimulasi \& Aspek Perkembangan Anak., Jakarta: Suyadi, Manajemen PAUD, Yogyakarta: Pustaka Pelajar.

Tematik Bagi Anak Usia Dini TK/RA dan Anak Kelas Awal SD/MI. Tutor dan Pengelola Pendidikan Anak Usia Dini, di BPPLSP Regional III Yogyakarta: Deepublish. 